\title{
Use of Emergency Medical Services by headache patients in a Greek metropolitan population
}

\author{
Panagiotis Kyriakidis*, Chrysanthi Bouziani, Zoi Dimarelou, \\ Konstantinos Lysitsas, Ioannis Gravas, Georgios Georgiadis, Jobst Rudolf and \\ Iakovos Tsiptsios
}

Address: Department of Neurology, General Hospital "Papageorgiou", Thessaloniki, Greece

* Corresponding author

\author{
from International Society on Brain and Behaviour: 3rd International Congress on Brain and Behaviour \\ Thessaloniki, Greece. 28 November - 2 December 2007 \\ Published: 17 April 2008 \\ Annals of General Psychiatry 2008, 7(SuppI I):SI77 doi:I0.II86/I744-859X-7-SI-SI 77
}

This abstract is available from: http://www.annals-general-psychiatry.com/content/7/SI/SI77

(C) 2008 Kyriakidis et al.; licensee BioMed Central Ltd.

\section{Background}

In the absence of effective pre-hospital health care facilities in Greece, patients with acute or chronic pain are forced to present immediately to the Emergency Outpatient Departments (EOD) of the on-call public hospitals. Thus, the treatment of headache patients may result in a relevant increase in the burden of work of the EOD.

\section{Materials and methods}

In an open prospective study design, epidemiological and clinical data were collected from all patients presenting with headache as their main symptom at the Emergency Outpatient Department (EOD) of Papageorgiou Hospital, a tertiary health care facility in metropolitan Thessaloniki, from August 2006 to January 2007.

\section{Results}

During the study period, a total of 2813 patients presented at the EOD. $420(14,9 \%)$ of those patients complained about headache as their main symptom. They were 133 (31,6\% of headaches) men, 291 (68,4\%) women, with a mean age of 36,6 years in male and 39,7 years in female headache patients. A primary headache was diagnosed in $214(50,9 \%)$ patients, secondary headache in $101(24,0 \%)$ patients and $105(25,1 \%)$ patients did not fulfil the diagnostic criteria for a distinct headache. $65(15,4 \%)$ patients were admitted to hospital, about half of them $(\mathrm{n}=30,7,1 \%)$ to a one day care unit, and $35(8,30 \%)$ to a ward). $24(5,7 \%)$ patients arrived with public emergency transport services, but only 11 were admitted to hospital.

\section{Conclusions}

Subjective and objective severity of headache consi-derably increase the burden of the local EOD to a degree that turns use of EOD into misuse. 